\title{
How Can We Apply the New American Thyroid Association Treatment Guidelines for Children and Adolescents with Thyroid Cancer to Improve Patient Management?
}

\section{Novel Insights into Clinical Experience}

Andrew J Bauer, ${ }^{1}$ Gary L Francis, ${ }^{2}$ Steven Waguespack, ${ }^{3}$ Donald Zimmerman, ${ }^{4}$ Sowmya Krishnan, ${ }^{5}$ Emily Breidbart, ${ }^{6}$ Pushpa Viswanathan, ${ }^{7}$ Ryan J McDonough, ${ }^{8}$ Katie Barger, ${ }^{8}$ Yun Yan, ${ }^{8}$ Jennifer K Yee, ${ }^{9}$ Allison Bauman, ${ }^{10}$ Jose Jimenez-Vega, ${ }^{11}$ Susan R Rose, ${ }^{11}$ Philippe F Backeljauw ${ }^{11}$ and Ron Newfield ${ }^{12}$

1. Children's Hospital of Philadelphia, Philadelphia, PA, US; 2. Children's Hospital of Richmond at Virginia Commonwealth University, Richmond, VA, US; 3. MD Anderson Cancer Treatment Center, University of Texas, Houston, TX, US; 4. Lurie Children's Hospital of Chicago, Chicago, IL, US; 5. University of Oklahoma Health Science Center, Oklahoma City, OK, US; 6. Columbia University/New York-Presbyterian, New York, NY, US; 7. Children's Hospital of Pittsburgh of University of Pittsburgh Medical Center, Pittsburgh, PA, US; 8. Children's Mercy Hospital, Kansas City, MO, US; 9. Harbor- UCLA Medical Center, Torrance, CA, US; 10. Cohen Children's Medical Center of New York, NY, US; 11. Cincinnati Children's Hospital Medical Center, University of Cincinnati, Cincinnati, OH, US; 12. Rady Children's Hospital, University of California, San Diego, San Diego, CA, US

\begin{abstract}
Background: Ultrasound reveals thyroid abnormalities in $18 \%$ of children and adolescents, of which, $22 \%$ are malignant. This creates a dilemma for practitioners who must distinguish lesions that require removal (high risk for malignancy) from lesions that can be observed (low risk for malignancy). Furthermore, treatment of children with differentiated thyroid cancer (DTC) is evolving. Previous treatments were based on adult protocols prescribing total thyroidectomy, lymph node dissection, and radioactive iodine (RAI) ablation for children with DTC, regardless of disease extent. This achieved excellent disease-free survival but high, and potentially avoidable, surgical and medical complications including an increase in secondary non-thyroid malignancies. Methods: This manuscript is a synopsis of cases presented during a symposium at the 2015 Pediatric Endocrine Society meeting (San Diego, CA) with recommendations based on the American Thyroid Association (ATA) management guidelines for children and adolescents with thyroid nodules and DTC. Results: The cases were selected to demonstrate application of the guidelines across a variety of pediatric patients with DTC highlighting key points of the ATA guidelines. The cases will assist practitioners in learning how to apply these guidelines to patient management. Conclusion: Treatment of children with thyroid nodules and DTC is evolving. Current guidelines emphasize the importance of surgery by experienced teams and deferral of RAI ablation for low-risk patients.
\end{abstract}

\section{Keywords}

Pediatric, thyroid, cancer, treatment, guidelines

\footnotetext{
Disclosure: Andrew J Bauer, Gary L Francis, Steven Waguespack, Donald Zimmerman, Sowmya Krishnan, Emily Breidbart, Pushpa Viswanathan, Ryan J McDonough, Katie Barger, Yun Yan, Jennifer K Yee, Allison Bauman, Jose Jimenez-Vega, Susan R Rose, Philippe F Backeljauw, and Ron Newfield have nothing to declare in relation to this article. Andrew J Bauer, Gary L Francis, and Steven Waguespack are members of the Pediatric Endocrine Society. Acknowledgements: This material was presented in part during the April, 2015 meeting of the Pediatric Endocrine Society in San Diego, CA, US. All recommendations are reproduced with permission of Mary Ann Liebert, Inc. 140 Huguenot St., New Rochelle, NY 10801-5215.

Compliance with Ethics: All procedures were followed in accordance with the responsible committee on human experimentation and with the Helsinki Declaration of 1975 and subsequent revisions, and informed consent was received from the patients involved in this case study.

open Access: This article is published under the Creative Commons Attribution Noncommercial License, which permits any noncommercial use, distribution, adaptation, and reproduction provided the original author(s) and source are given appropriate credit.

Received: February 18, 2016 Accepted: March 29, 2016 Citation: US Endocrinology, 2016;12(1):39-51 DOI: http://doi.org/10.17925/USE.2016.12.01.39 Correspondence: Gary L Francis, Professor and Chief, Division of Pediatric Endocrinology and Metabolism, Children's Hospital of Richmond at Virginia Commonwealth University, PO BOX 980140, Richmond, VA 23098, US. E: Gary.Francis@vcuhealth.org
} 
Thyroid nodules and thyroid cancers are more common in children than has been previously appreciated, and represent a significant health issue. Older studies used palpation to identify thyroid nodules and reported a childhood prevalence of $2 \%$. However, high-resolution ultrasound identifies thyroid abnormalities in $18 \%$ of children. ${ }^{1}$ Ultrasound also detects thyroid nodules in 13-31.5\% of children with autoimmune thyroiditis (AIT). ${ }^{2,3}$ Once a thyroid nodule is identified, the overall risk of malignancy is higher for children (22\%) than for adults (5-10\%). ${ }^{4}$ Ultrasound has been used routinely for more than a decade, and during that time the incidence of differentiated thyroid cancer (DTC) has been increasing among those of all ages, including children. The most recent data from the Surveillance, Epidemiology, and End Results (SEER) Program report an annual incidence for adolescents of approximately 25 cases/million/year. ${ }^{5}$ These data suggest that approximately 400,000 children and adolescents in the US have a solid thyroid nodule and 100,000 have DTC. ${ }^{2}$

For decades, treatment of children with DTC was based on adult treatment guidelines. ${ }^{6}$ The majority of children with DTC already have lymph node involvement at the time of diagnosis (80\%) and many (20\%) have pulmonary metastases. Based on this metastatic profile, children were routinely treated with total thyroidectomy (TT), Iymph node dissection (LND), and radioactive iodine (RAl) ablation. Although this therapy was highly successful in treating disease (disease-specific mortality was only $2 \%$ ), it was associated with a high rate of complications and an increased risk for secondary malignancies. ${ }^{7}$ These second malignancies resulted in excess overall mortality (60\% overall survival at age 60 years versus $75 \%$ overall survival for controls) and have led us to reconsider the universal prescription of RAl for children with low-risk DTC.?

Previous treatment was also designed to completely eradicate disease. Children with persistent disease were administered RAI on a scheduled annual basis until the diagnostic whole-body RAI scan (dxWBS) showed no RAI uptake and the serum thyroglobulin ( $\mathrm{Tg}$ ) was undetectable. However, $30-45 \%$ of children with pulmonary metastases do not become free from disease after multiple treatments, but develop stable-persistent disease. ${ }^{8}$ For them, 10-year survival remains excellent (100\%) and the majority do not progress (five-year progression-free survival [PFS] was 65-70\%). Important data from Biko, et al. ${ }^{9}$ have also shown that total body disease burden (as reflected by serum $\mathrm{Tg}$ levels) may continue to decline for many years after RAl therapy. ${ }^{9}$ They followed 20 children who were diagnosed with papillary thyroid cancer (PTC) and extensive pulmonary metastases. Patients received a mean of 5.5 therapeutic courses of RAl, accumulating $24.2 \mathrm{GBq}$ (654 mCi). During that time, serum Tg declined as expected. However, RAI therapy was prematurely discontinued even though the patients had a large persistent tumor burden (mean serum Tg level approximately $100 \mu \mathrm{g} / \mathrm{L}$ ). Despite the lack of continued treatment, the serum $\mathrm{Tg}$ level continued to decline and became undetectable in many.

For these reasons, a more appropriate risk-stratified treatment and rational end-point for therapy were needed for children. A similar strategy has been successfully employed for adults. ${ }^{10,11}$ Ideally, children with extensive lymph node involvement and pulmonary metastases would still undergo TT plus LND and RAl, but children with less extensive disease (i.e. disease confined to the gland) would receive less extensive therapy. All children would have an assessment of the individual treatment response and more appropriate end-points. Such

\section{Table 1: Key changes in management of children with differentiated thyroid cancer}

$\begin{array}{ll}\text { Management } & \text { Previous } \\ \text { Pre-operative } & \text { Rarely done. All patients } \\ \text { staging } & \begin{array}{l}\text { received similar treatment } \\ \text { regardless of extent of } \\ \text { disease }\end{array}\end{array}$

Thyroid Most underwent total

surgery thyroidectomy but some underwent sub-total

Lymph node Most patients had 'berrydissection picking' of cervical lymph nodes, removing only those that felt suspicious

Radioactive Almost all patients received iodine

Follow-up post-operative RAI to ablate the thyroid remnant or to treat persistent disease

Most patients were followed with annual dxWBS scan on an annual basis thyroidectomy

Current Guideline Sections and Recommendations

Staging is essential to identify patients who need central neck dissection and RAI therapy. Complete neck US and fine-needle aspiration of suspicious nodules and lymph nodes is recommended prior to surgery

Total thyroidectomy is the preferred surgery for all patients except those with small incidental PTC

Standardized central compartment lymph node dissection is recommended with lateral neck dissection for patients with disease identified in the lateral neck

RAl recommended for persistent disease but not for those at low-risk for recurrence

Routine dxWBS is not recommended unless there was disease identified on prior scans. Neck ultrasound and serum Tg are more sensitive. For Tg-antibody positive patients, serum Tg can be measured by tandem massspectrometry

End-point of Goal of therapy was to achieve Almost half of patients with therapy NED. This often required pulmonary metastases will not multiple treatments with RAl achieve NED after therapy but and high total life time 131 develop stable persistent disease Iodine exposure. RAI was given with low mortality. Repeat treatment on annual basis until no uptake should be offered to those with on dxWBS. progressive disease

dxWBS = diagnostic whole-body radioactive iodine scan; NED = no evidence of disease $P T C=$ papilliary thyroid cancer; $R A I=$ radioactive iodine; $T g=$ thyroglobulin.

individualized treatment would thereby limit the risk for complications and second malignancies. To address this need, The American Thyroid Association (ATA) empaneled an international, multidisciplinary task force to develop treatment guidelines for children and adolescents with thyroid nodules and cancers. This task force reviewed the available literature and developed evidence-based guidelines that have been recently published. ${ }^{12}$ Key changes in the management of children with DTC are highlighted in Table 1.

This risk-stratified approach generates several questions that must be addressed for each individual patient.

- Who needs TT, LND and RAl, and who can do just as well with less?

- What is a rational end-point for therapy, i.e. do we need all patients to have no evidence for disease in order to have excellent survival? 


\section{Table 2: Strength of recommendations based on available evidence ${ }^{13}$}

\begin{tabular}{|c|c|}
\hline Rating & Definition \\
\hline $\begin{array}{l}\text { A Strongly } \\
\text { recommends }\end{array}$ & $\begin{array}{l}\text { The recommendation is based on good evidence that the } \\
\text { service or intervention can improve important health outcomes. } \\
\text { Evidence includes consistent results from well-designed, well- } \\
\text { conducted studies in representative populations that directly } \\
\text { assess effects on health outcomes }\end{array}$ \\
\hline B Recommends & $\begin{array}{l}\text { The recommendation is based on fair evidence that the service } \\
\text { or intervention can improve important health outcomes. The } \\
\text { evidence is sufficient to determine effects on health outcomes, } \\
\text { but the strength of the evidence is limited by the number, } \\
\text { quality, or consistency of the individual studies; generalizability } \\
\text { to routine practice; or indirect nature of the evidence on health } \\
\text { outcomes }\end{array}$ \\
\hline C Recommends & The recommendation is based on expert opinion \\
\hline $\begin{array}{l}\text { D Recommends } \\
\text { against }\end{array}$ & The recommendation is based on expert opinion \\
\hline $\begin{array}{l}\text { E Recommends } \\
\text { against }\end{array}$ & $\begin{array}{l}\text { The recommendation is based on fair evidence that the service } \\
\text { or intervention does not improve important health outcomes or } \\
\text { that harms outweigh benefits }\end{array}$ \\
\hline $\begin{array}{l}\text { F Strongly } \\
\text { recommends } \\
\text { against }\end{array}$ & $\begin{array}{l}\text { The recommendation is based on good evidence that the } \\
\text { service or intervention does not improve important health } \\
\text { outcomes or that harms outweigh benefits }\end{array}$ \\
\hline $\begin{array}{l}\text { I Recommends } \\
\text { neither for nor } \\
\text { against }\end{array}$ & $\begin{array}{l}\text { The panel concludes that the evidence is insufficient to } \\
\text { recommend for or against providing the service or intervention } \\
\text { because evidence is lacking that the service or intervention } \\
\text { improves important health outcomes, the evidence is of poor } \\
\text { quality, or the evidence is conflicting. As a result, the balance of } \\
\text { benefits and harms cannot be determined }\end{array}$ \\
\hline
\end{tabular}

- How can we tell if therapy is working and how long will it work, i.e. do we need annual RAl therapy or should we wait until all effects from prior treatments have occurred?

\section{Materials and methods}

Recognizing the need for providers to gain experience in applying these guidelines to the care of children with DTC, the Program Committee of the Pediatric Endocrine Society invited a panel of experts to review and discuss representative cases of pediatric thyroid nodules and cancers at their annual meeting in April, 2015. Eight cases were submitted. The cases are presented here, and each discussion demonstrates application of the ATA pediatric guidelines to patient care with citation of the pertinent recommendations from the ATA guideline and the strength of the evidence using a modified schema from the US Preventive ServicesTask Force (Table 2). ${ }^{13}$

The ATA pediatric guidelines represent a paradigm shift in the care of children with DTC. ${ }^{12}$ Key evaluation and management points from the pediatric guidelines include the following.

- All pediatric patients are at low risk for mortality, but are classified as low-, intermediate-, or high-risk for persistent or recurrent disease based on pre- and post-operative staging.

- Pre-operative staging is recommended to facilitate selection of appropriate surgery. The majority of children will undergo TT and

\section{Table 3: Tumor, node, and metastasis classification system for differentiated thyroid carcinoma}

\begin{tabular}{|c|c|c|}
\hline \multicolumn{3}{|c|}{ Primary Tumor (T) } \\
\hline TX & & Size not assessed, limited to the thyroid \\
\hline \multirow[t]{2}{*}{$\mathrm{T} 1$} & T1a & $\leq 1 \mathrm{~cm}$, limited to the thyroid \\
\hline & $\mathrm{T} 1 \mathrm{~b}$ & $>1 \mathrm{~cm}$ but $\leq 2 \mathrm{~cm}$, limited to the thyroid \\
\hline \multicolumn{2}{|l|}{$\mathrm{T} 2$} & $>2 \mathrm{~cm}$ but $\leq 4 \mathrm{~cm}$, limited to the thyroid \\
\hline \multicolumn{2}{|l|}{ Т3 } & $\begin{array}{l}>4 \mathrm{~cm} \text {, limited to the thyroid, or any tumor with minimal } \\
\text { extrathyroidal extension }\end{array}$ \\
\hline \multirow[t]{2}{*}{ T4 } & T4a & $\begin{array}{l}\text { Tumor extends beyond the thyroid capsule to invade } \\
\text { subcutaneous soft tissues, larynx, trachea, esophagus, or } \\
\text { recurrent laryngeal nerve }\end{array}$ \\
\hline & T4b & $\begin{array}{l}\text { Tumor invades prevertebral fascia or encases carotid artery or } \\
\text { mediastinal vessels }\end{array}$ \\
\hline \multicolumn{3}{|c|}{ Lymph Nodes (N) } \\
\hline \multicolumn{2}{|l|}{ NX } & Regional lymph nodes not assessed \\
\hline \multicolumn{2}{|l|}{ NO } & No regional lymph node metastasis \\
\hline \multirow[t]{2}{*}{ N1 } & N1a & $\begin{array}{l}\text { Metastasis to Level VI (pretracheal, para tracheal, and } \\
\text { prelaryngeal/ Delphian lymph nodes) }\end{array}$ \\
\hline & $\mathrm{N} 1 \mathrm{~b}$ & $\begin{array}{l}\text { Metastasis to unilateral, bilateral, or contralateral cervical Levels } \\
\text { I, II, III, IV, or V) or retropharyngeal or superior mediastinal lymph } \\
\text { nodes (Level VII) }\end{array}$ \\
\hline \multicolumn{3}{|c|}{ Distant Metastasis (M) } \\
\hline \multicolumn{2}{|l|}{$\mathrm{MX}$} & Distant metastasis not assessed \\
\hline \multicolumn{2}{|l|}{ MO } & No distant metastasis \\
\hline \multicolumn{2}{|l|}{ M1 } & Distant metastasis \\
\hline
\end{tabular}

central compartment lymph node dissection (CLND) but more extensive LND may be required if disease is identified beyond the central neck (level VI). Removal of only suspicious lymph nodes (berry-picking) is not recommended. Cross-sectional imaging is recommended for patients with extensive bulky neck disease that precludes adequate visualization, especially if disease is encroaching on or into the aerodigestive tract. Pre-operative chest radiograph or computerized tomography (CT) of the chest is recommended to identify pulmonary metastases.

- Post-operative staging is recommended and utilizes standard tumor, node, and metastasis (TNM) nomenclature (Table 3) to describe the extent of disease.

- For patients at low risk for recurrence (disease confined to the gland with no lymph node metastasis (American Joint Committee on Cancer [AJCC] TNM designation of N0) or incidental central neck lymph node metastasis (N1a disease), post-operative staging may only require serum $\mathrm{Tg}$.

- Patients at intermediate risk for recurrence based on the presence of extensive central lymph node metastasis (N1a disease) or minimal metastasis to lateral neck lymph nodes (N1b disease) usually require Thyroid stimulating hormone (TSH)-stimulated Tg and dxWBS (123|)

- Patients at high risk for recurrence based on the presence of extensive lateral neck lymph node metastasis (N1b disease) or 


\section{Table 4: American Thyroid Association pediatric thyroid cancer risk levels and post-operative management in children with papillary thyroid carcinoma}

\begin{tabular}{|c|c|c|c|c|}
\hline $\begin{array}{l}\text { ATA Risk } \\
\text { Level* }\end{array}$ & Definition & $\begin{array}{l}\text { Initial Post-operative } \\
\text { Staging }^{\dagger}\end{array}$ & TSH Goal‡ & $\begin{array}{l}\text { Surveillance of Patients With No } \\
\text { Evidence of Disease }^{\S}\end{array}$ \\
\hline $\begin{array}{l}\text { ATA Pediatric } \\
\text { Low-Risk }\end{array}$ & $\begin{array}{l}\text { Disease grossly confined to the thyroid with } \\
\text { No/Nx disease or patients with incidental N1a } \\
\text { disease (microscopic metastasis to a small } \\
\text { number of central neck lymph nodes) }\end{array}$ & Tgी & $0.5-1.0 \mathrm{mIU} / \mathrm{L}$ & $\begin{array}{l}\text { US at } 6 \text { months post-operatively and then } \\
\text { annually x } 5 \text { years } \\
\text { Tgף on LT4 every } 3-6 \text { months for } 2 \text { years } \\
\text { and then annually }\end{array}$ \\
\hline $\begin{array}{l}\text { ATA Pediatric } \\
\text { Intermediate Risk }\end{array}$ & Extensive N1a or minimal N1b disease & $\begin{array}{l}\text { TSH-Stimulated Tgף and } \\
\text { diagnostic }{ }^{123} \text { I scan in most } \\
\text { patients }\end{array}$ & $0.1-0.5 \mathrm{mIU} / \mathrm{L}$ & $\begin{array}{l}\text { Ultrasound at } 6 \text { months post-operatively, every } \\
\text { 6-12 months for } 5 \text { years, and then less frequently } \\
\text { Tgף on LT4 every } 3-6 \text { months for } 3 \text { years and then } \\
\text { annually Consider TSH-stimulated Tgף } \pm \text { diagnostic } \\
{ }^{123} \text { I scan in } 1-2 \text { years in patients treated with }{ }^{131} \text { | }\end{array}$ \\
\hline $\begin{array}{l}\text { ATA Pediatric } \\
\text { High Risk }\end{array}$ & $\begin{array}{l}\text { Regionally extensive disease (extensive } \\
\text { N1b) or locally invasive disease (T4 tumors), } \\
\text { with or without distant metastasis }\end{array}$ & $\begin{array}{l}\text { TSH-Stimulated Tg" and } \\
\text { diagnostic }{ }^{123} \text { scan in all patients }\end{array}$ & $<0.1 \mathrm{mIU} / \mathrm{L}$ & $\begin{array}{l}\text { Ultrasound at } 6 \text { months post-operatively, every 6-12 } \\
\text { months for } 5 \text { years, and then less frequently } \\
\text { Tgף on LT4 every } 3-6 \text { months for } 3 \text { years and then } \\
\text { annually TSH-stimulated Tg" } \pm \text { diagnostic }{ }^{123} \text { scan } \\
\text { in 1-2 years in patients treated with }{ }^{131}\end{array}$ \\
\hline
\end{tabular}

Please refer to Table 3 for American Joint Committee on Cancer tumor, node, and metastasis classification system. ATA = American Thyroid Association; FTC = follicular thyroid

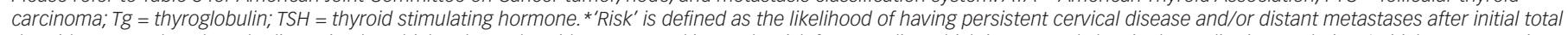

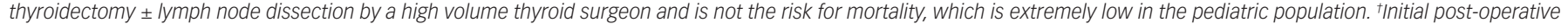
staging that is done within 12 weeks after surgery. ${ }^{*}$ These are initial targets for TSH suppression and should be adapted to the patient's known or suspected disease status: in ATA pediatric intermediate- and high-risk patients who have no evidence of disease after three to five years of follow up, the TSH can be allowed to rise to the low normal range. spost-operative surveillance implies studies done at six months after the initial surgery and beyond in patients who are believed to be disease free; the intensity of follow up and extent of diagnostic studies are determined by initial post-operative staging, current disease status, and whether or not ${ }^{131}$ l was given; may not necessarily apply to patients with known or suspected residual disease or FTC. "Assumes a negative TgAb; in TgAb-positive patients, consideration can be given (except in patients with T4 or M1 disease) to deferred post-operative staging to allow time for TgAb clearance. Used with the permission of Mary Ann Liebert, Inc. 140 Huguenot St., New Rochelle, NY 10801-5215

invasive tumors with extra thyroidal extension in the peri-thyroidal soft tissue space (T4), with or without distant metastases require TSH-stimulated Tg and dxWBS (123) in all cases.

- Therapy and follow up are individualized based on the extent of disease and response to prior treatments (Table 4).

\section{Case review \\ Case one}

A 13-year-old male had an enlarged, firm thyroid gland $(8.4 \mathrm{~cm})$, normal serum thyrotropin (TSH, $1.9 \mu \mathrm{IU} / \mathrm{ml}$ ), and neck ultrasound that showed a heterogeneously enlarged thyroid with hyperechoic foci throughout the gland associated with multiple enlarged lymph nodes with increased peripheral vascularity. This case demonstrates several important points in the evaluation of children with goiter or thyroid nodules.

The diffusely enlarged, heterogeneous, and hypervascular thyroid with multiple enlarged lymph nodes is a common presentation for PTC in children who do not always have a discrete nodule. 14,15

- This is a large lesion and although size alone is not a major criterion for fine-needle aspiration (FNA) in children; considering history, family history, and US features are important. ${ }^{16-18}$

- Enlarged lymph nodes with increased peripheral vascularity are a risk factor for PTC. ${ }^{14,15}$

Due to a concern for possible DTC, FNA was performed but was nondiagnostic. The ATA pediatric guidelines suggest caution in evaluating large lesions $(>4 \mathrm{~cm}$ ) by FNA due to a high probability of sampling error. Furthermore, non-diagnostic FNA may be associated with a higher probability of malignancy in children. The FNA should either be repeated after three months to avoid confusion caused by cytologic changes which occur during post-FNA reparation, or the lesion should be removed. ${ }^{19,20}$

\section{RECOMMENDATION 5}

The evaluation and treatment of thyroid nodules in children should be the same as in adults with the exceptions that: 1. Ultrasound characteristics and clinical context should be used rather than size alone to identify nodules that warrant FNA, 2. All FNA in children should be performed under ultra sound-guidance, 3. Pre-operative FNA of a hyper functioning nodule in a child is not warranted as long as the lesion is removed, 4. A diffusely infiltrative form of PTC may occur in children and should be considered in a clinically suspicious gland, and 5. Surgery (lobectomy + isthmusectomy) is favored over repeat FNA for most nodules with indeterminate cytology. ${ }^{1}$ Recommendation rating: $\mathrm{B}$

Based on the potential for error in the FNA, the patient was closely followed, as suggested by the guidelines. ${ }^{12}$

Repeat ultrasound confirmed micro-calcifications which are highly suspicious for PTC. ${ }^{14,15}$ Neck CT showed thyromegaly and enlarged cervical lymph nodes, prompting excisional lymph node biopsy that confirmed PTC. In this case, FNA of the involved lymph node and Tg assay of the FNA needle-wash were other options ${ }^{21}$ that are less invasive, highly accurate, and can detect DTC in lymph nodes even in the presence of high levels of serum $\mathrm{Tg}$ and Tg-antibody (Tg-Ab). ${ }^{21-25}$ 


\section{SECTION B4}

Insufficient or non-diagnostic cytopathology refers to a specimen with limited cellularity, absence of follicular cells or poor fixation and preservation. Repeat FNA is an option in children but should be delayed for a minimum of 3-months in order to decrease the potential for atypical cellular features that may arise during the reparative process. In adults, the risk of malignancy in indeterminate nodules ranges from $~ 5-15 \%$ in the AUS/FLUS category to $15-30 \%$ in the follicular neoplasm or suspicious for neoplasm group. The limited data available suggest these indeterminate FNA categories account for $~ 35 \%$ of pediatric FNA and that, in children, $28 \%$ of AUS/FLUS lesions and $58 \%$ of suspicious for follicular or Hürthle cell neoplasm are malignant. Due to the apparent increased probability of malignancy among these indeterminate categories in children, the task force recommends definitive surgery (lobectomy + isthmusectomy) for indeterminate FNA findings in children. ${ }^{1}$ Recommendation rating: $\mathrm{B}$

\section{RECOMMENDATION 8}

Benign lesions should be followed by serial ultrasound and undergo repeat FNA if suspicious features develop or the lesion continues to grow. Lobectomy should be considered in all apparently benign solid thyroid nodules $>4 \mathrm{~cm}$, those lesions demonstrating significant growth, or in the presence of other clinical concerns for malignancy. ${ }^{1}$ Recommendation rating: $\mathrm{B}$

Once a diagnosis of PTC is made, pre-operative staging is recommended for all children, including either chest radiograph or non-contrast chest CT. In this case, both neck and chest CT were performed and showed no indication of pulmonary metastases.

\section{RECOMMENDATION 10}

A comprehensive neck ultrasound to interrogate all regions of the neck is required in order to optimize the pre-operative surgical plan. FNA of suspicious lateral neck lymph nodes is recommended. Anatomic imaging by MRI or CT with contrast should be considered in patients with large or fixed thyroid masses, vocal cord paralysis, or bulky metastatic lymphadenopathy in order to optimize surgical planning. ${ }^{1}$ Recommendation rating: $A$

As recommended in the guidelines, the patient underwent TT and central neck LND. With such a large lesion, there is an increased risk for metastasis to the lateral neck and beyond. Surgical exploration of the lateral neck is not recommended, rather FNA should beperformed with planned, therapeutic compartment-based, lateral neck dissection, performed if FNA confirms metastasis to the lateral neck lymph nodes. ${ }^{12}$

Pathology confirmed PTC measuring $8.4 \mathrm{~cm}$, adherent to the sternothyroid muscle, and metastatic to lymph nodes in the right (levels 2a, 2b, 3, 4, and 5) and left lateral (levels 3 and 4) neck. There was minimal extra-thyroidal invasion, but extensive lymphovascular invasion, resulting in TNM classification: pT3N1b.

\section{RECOMMENDATION 11}

For the majority of children, $\Pi$ is recommended. This is based on multiple studies showing an increased incidence of bilateral and multi-focal disease. Bilateral lobar resection compared with lobectomy has been shown to decrease the risk for persistent/ recurrent disease. Recommendation rating: $A$

\section{RECOMMENDATION 12(A)}

Central neck dissection (CND) is recommended for clinical evidence of gross extra-thyroidal invasion and/or loco-regional metastasis and may be associated with a reduced need for second surgeries and an increase in disease-free survival (DFS). Recommendation rating: $B$

\section{RECOMMENDATION 12(B)}

For PTC and no clinical evidence of gross extra-thyroidal invasion and/or loco-regional metastasis, prophylactic CND may be selectively considered based upon tumor focality and size and the experience of the surgeon. For patients with unifocal disease, ipsilateral CND, with pursuit of contralateral CND based on intra-operative findings, may help balance the risks. Recommendation rating: $\mathrm{C}$

\section{RECOMMENDATION 12(C)}

Compartment-oriented resection is recommended for LND.

"Berry picking" and palpation to detect metastatic disease are not recommended. Recommendation rating: $\mathrm{A}$

\section{RECOMMENDATION 13}

Confirmation of disease in the lateral neck is recommended prior to surgery. Routine prophylactic lateral neck dissection is not recommended. However, lateral neck dissection should be performed on patients with evidence of metastases to the lateral neck. Recommendation rating: $\mathrm{B}$

As recommended by the guidelines, post-operative staging was performed. A post-operative dxWBS showed uptake in the thyroid bed and cervical lymph nodes but not lungs. The stimulated serum Tg was $228 \mathrm{ng} / \mathrm{ml}$ with a TSH level of $39.8 \mathrm{ulU} / \mathrm{ml}$. However, the serum Tg-Ab was positive $(1.8 \mathrm{IU} / \mathrm{ml}$, reference range $0.0-0.9 \mathrm{IU} / \mathrm{ml})$.

In adults with PTC, the magnitude of serum Tg correlates with location and histology of DTC. ${ }^{26}$ Although this has not yet been replicated in children, the magnitude of the serum $\mathrm{Tg}$ in this case suggested an increased risk of pulmonary metastases. However, the presence of even low titers of Tg-Ab can interfere with the Tg assay leading to falsely low (more frequent) or falsely high serum $\operatorname{Tg}^{27,28}$

\section{RECOMMENDATION 20}

Based on the lack of data comparing empiric treatment and treatment informed by dosimetry, we are unable to recommend for or against either approach in most patients. Many experts provide the first activity of ${ }^{131}$ l based on an empiric estimate and reserve dosimetry for patients with diffuse pulmonary metastases or subsequent activities of ${ }^{131}$ I. However, dosimetry can be considered prior to the first ${ }^{131}$ treatment in small children and patients with limited bone marrow reserve. Due to the differences in body size and iodine clearance in children compared with adults, it is recommended that all activities of ${ }^{131}$ I should be calculated by experts with experience in dosing children. ${ }^{1}$ Recommendation rating: । 
The dxWBS showed uptake in the thyroid bed and several cervical lymph nodes, and the patient was treated with $154 \mathrm{mCi}{ }^{131}$ iodine $\left({ }^{131} \mathrm{I}\right)$. Posttherapy scan showed diffuse pulmonary metastases. The dxWBS is not as sensitive as the post-therapy scan. ${ }^{29}$ Thus, a negative dxWBS is fairly common in a child with pulmonary metastases and should not imply absence of lung disease. Pulmonary metastases would be typical based on the TNM classification, the presence of extensive Iympho-vascular invasion, lymph node involvement, and the magnitude of serum Tg.

The ATA pediatric thyroid cancer guidelines offer no standardized doses of RAI for children, but indicate that doses are adjusted by the ratio of their body size compared to that of an adult. ${ }^{1}$

The patient was placed on suppressive levothyroxine and followed. Fortunately, the TSH-stimulated Tg has declined from 228 to $2.3 \mathrm{ng} / \mathrm{ml}$, indicating an excellent response. Serum Tg may continue to decline over 18 months in most cases. ${ }^{30}$ The guideline suggests that continued observation is warranted. ${ }^{1}$ Should the Tg increase, then repeat staging would be required to determine if there is recurrent disease in the neck or lungs.

\section{Case two}

A 17-year-old male had dysphagia, enlargement of the neck, and normal thyroid function, but ultrasound showing a markedly enlarged and heterogeneous right thyroid lobe without a distinct nodule but with hyperechoic foci throughout, which were concerning for microcalcifications. FNA was consistent with PTC. He underwent $\Pi$ with central compartment LND. Pathology revealed diffuse-sclerosing variant of PTC (dsVPTC) with metastasis in 21/25 Iymph nodes. The post-operative serum $\mathrm{Tg}$ was undetectable but the $\mathrm{Tg}$-Ab was positive $(181.3 \mathrm{IU} / \mathrm{mL}$; normal 0-4 IU/mL). Post-operatively the patient was placed on thyroid hormone suppressive therapy.

Two months later, a spot urine iodine was $591.8 \mu \mathrm{g} / \mathrm{mL}$ (normal range 26.0-705.0 $\mathrm{\mu g} / \mathrm{L}$ ). The patient was started on a low-iodine diet, the levothyroxine was discontinued and the serum TSH increased ( $92 \mathrm{mIU} / \mathrm{L}$ ). Due to the dsvPTC with extensive N1b disease, the patient was given $106.7 \mathrm{mCi}{ }^{131}$ iodine. dxWBS was not performed. Unfortunately, three hours later, he had a single episode of emesis. The post-therapy scan (RxWBS) five days later showed no tracer uptake.

This case raises several questions for management.

- First, dsVPTC is not a rare lesion in children. It tends to invade the entire lobe or gland and presents with diffuse thyroid enlargement and not a thyroid nodule. ${ }^{31-33}$ Suspicion should be raised in patients with a particularly firm gland, abnormal palpable cervical lymph nodes, or as in this case, the presence of micro-calcifications without a distinct nodule. The neck ultrasound did not reveal any suspicious lateral neck lymph nodes so the patient had a central LND.

- A thorough pre-operative staging with a neck US that examines all levels of the lateral neck (levels 2, 3, 4, and 5) as well as axial imaging with neck CT or MRI might have revealed extensive neck disease that would have prompted surgical re-exploration prior to the RAl therapy. RAl is effective for treatment of microscopic pulmonary metastases and small residual neck disease but is not useful for treatment of large neck masses. ${ }^{8,34}$
- Prior to therapy the urine iodine was elevated to $591.8 \mu \mathrm{g} / \mathrm{L}$, which is higher than the pre-RAl treatment target of $<75 \mu \mathrm{g} / \mathrm{L} .{ }^{35} \mathrm{~A}$ repeat urine iodine was not performed to confirm that the urine iodine level decreased prior to RAI administration and if it were still elevated, this may have prevented tumor RAI uptake. The effectiveness of RAl might have been further reduced by the patient's emesis. In retrospect, waiting until the urine iodine was confirmed to be $<75 \mu \mathrm{g} / \mathrm{L}$ may have facilitated treatment. Pre-treating with ondansetron may have prevented nausea and vomiting, which are common following RAl.

\section{RECOMMENDATION 25(A)}

During follow up of children with PTC who are suspected to have residual disease, a dxWBS can be used to inform the decision of whether or not to use ${ }^{131}$ and the activity of ${ }^{131}$ to be administered. Recommendation rating: $\mathrm{C}$

\section{RECOMMENDATION 25(B)}

A dxWBS should be performed in children with ATA Pediatric Highrisk disease who were previously treated with ${ }^{131}$ I or known to have iodine-avid metastatic disease based upon a previous post-treatment scan. The dxWBS should be obtained after at least 12 months of clinical follow-up, and deferred even longer in those children who continue to demonstrate a clinical response to previous treatment. Recommendation rating: $\mathrm{B}$

\section{RECOMMENDATION 25(C)}

Once a negative $d x W B S$ is obtained, there is no benefit from serial dxWBS to survey for disease recurrence as long as the patient otherwise remains without clinical evidence of disease. Recommendation rating: $\mathrm{B}$

The patient had a repeat neck ultrasound six months later and FNA of suspicious lymph nodes revealed persistent metastatic PTC in the neck. A right lateral neck dissection was performed with PTC confirmed in 12/47 Iymph nodes (2/14 Level IIA, 0/11 Level IIB, 7/12 Level III, 3/7 Level IV, 0/3 Level V). The $\mathrm{Tg}$-Ab remains elevated (166.5 IU/ml, normal range $0-4 \mathrm{IU} / \mathrm{mL}$ ) but the most recent serum $\mathrm{Tg}$ is undetectable by liquid chromatography-mass spectrometry (LC-MS/MS, ARUP Laboratories, 500 Chipeta Way, Salt Lake City, UT 84108-1221) and dxWBS one year later remains negative. Recent data suggest that the Tg measured by LC-MS/MS is not affected by the presence of Tg-Ab and is a good tumor marker for Tg-Ab positive patients as is the Tg-Ab titer which should decline in patients without residual disease. ${ }^{36}$ The undetectable Tg by LC-MS/MS suggests the patient may be free from disease ${ }^{37,38}$ in which case the Tg-Ab will continue to decline due to lack of thyroid antigens that maintain the immune stimulus. However, it takes an average of three years for the Tg-Ab to become negative in adults. ${ }^{39}$ If the Tg by LC-MS/MS was obtained under TSH-stimulation then the patient is highly likely to be free from disease.

\section{Case three}

A six-year-old Asian female had been diagnosed with stage 4 neuroblastoma at the age of two years. Sixteen months following treatment (tumor resection, chemotherapy, autologous bone marrow transplant, external beam radiation therapy to the abdominal tumor site [total 35Gy -estimated 3cGy to thyroid] and metaiodobenzylguanidine [MIBG] radionuclide whole body scanning [estimated 60 cGy to thyroid]), a thyroid nodule was incidentally detected on routine chest CT. There was no family history of neuroblastoma, thyroid nodules, or thyroid cancer. 
She underwent lobectomy, followed by completion thyroidectomy revealing a unifocal, $3.2 \mathrm{~cm}$, follicular variant papillary thyroid carcinoma (FVPTC) with focal capsular invasion but without Iympho-vascular invasion. The tumor margins were free from disease.

Following surgery her serum $\mathrm{Tg}$ was $3 \mathrm{ng} / \mathrm{ml}(\mathrm{TSH}=1.98 \mathrm{ulU} / \mathrm{ml}$ and negative $\mathrm{Tg}$ antibody) but four months later the serum $\mathrm{Tg}$ increased to $8.4 \mathrm{ng} / \mathrm{ml}$ (TSH = $1.4 \mathrm{ulU} / \mathrm{ml}$ ). Neck US identified a suspicious lesion in the thyroid bed that was removed and confirmed persistent FVPTC Subsequently, the serum $\mathrm{Tg}$ declined to $0.3 \mathrm{ng} / \mathrm{ml}$.

This case raised several questions.

- Did the radiation exposure contribute or was this an 'incidental PTC'?

- What mutations do you expect to find in radiation associated PTC?

- Are there unique genetic associations between neuroblastoma and PTC?

- Is there a role for pre-operative staging and CND for an 'incidental' lesion of $3 \mathrm{~cm}$ ?

- What is an 'acceptable $\mathrm{Tg}^{\prime}$ ' after surgery?

- What is a 'concerning' rise in serum Tg?

Thyroid cancer is a common second malignancy in the Childhood Cancer Survivor Study, with a standardized incidence ratio of 11.3 (95\% confidence interval $[\mathrm{Cl}]=8.2-15.3) \cdot{ }^{40,41}$ Radiation exposure is associated with an increased risk for PTC but the peak incidence is 10-30 years after exposure. PTC that arise following radiation have a greater frequency of RET-PTC3 gene rearrangements than are found in spontaneous PTC. ${ }^{42}$ Treatment with alkylating agents or other chemotherapeutic agents is also associated with an increased risk for PTC, but only if the radiation dose is <20 Gy (alkylating agents [relative risk (RR) 3.25; 95\% Cl 0.9-14.9], anthracyclines [RR 4.5; 95\% Cl 1.4-17.8], bleomycin [RR 3.2; $95 \% \mathrm{Cl} 0.8-10.4]){ }^{40,43}$ Most relevant to this discussion, PTC is five times more common as a second malignancy following radiation therapy for neuroblastoma when compared with radiation therapy for any other primary malignancy. ${ }^{44}$ In a long-term follow-up study of 16 survivors of childhood neuroblastoma, $81 \%$ had thyroid hormone abnormalities, $56 \%$ had thyroid nodules and $12.5 \%$ had PTC. ${ }^{45,46}$ This suggests the possibility of shared genetic predisposition which was recently emphasized by publicaiton of heterozygous missense mutation in STK11 in both neuroblastoma and FVPTC implicating STK11 as a possible shared driver mutation. ${ }^{47}$

In this particular case, a $3 \mathrm{~cm}$ lesion in a six-year-old yr child is concerning and would not ordinarily be considered an 'incidental', lesion irrespective of how it was discovered. Pre-operative staging should be performed to ensure surgical planning that would increase the likelihood of complete surgical resection.

The goal following total thyroidectomy is to achieve a TSH-suppressed serum $\mathrm{Tg}<1.0 \mathrm{ng} / \mathrm{ml}$. In this case, the serum $\mathrm{Tg}$ was $3 \mathrm{ng} / \mathrm{ml}$ and increased to $8.4 \mathrm{ng} / \mathrm{ml}$ over four months, both of which suggested persistent disease that was later confirmed and removed. After the second surgery, the patient's serum Tg declined to $0.3 \mathrm{ng} / \mathrm{ml}$, which is reflective of successful resection. (See Recommendation $23 \mathrm{~A}-\mathrm{E}$ in case one).

\section{RECOMMENDATION 10}

A comprehensive neck ultrasound to interrogate all regions of the neck is required in order to optimize the pre-operative surgical plan. FNA of suspicious lateral neck lymph nodes is recommended. Anatomic imaging by MRI or CT with contrast should be considered in patients with large or fixed thyroid masses, vocal cord paralysis, or bulky metastatic lymphadenopathy in order to optimize surgical planning. ${ }^{12}$ Recommendation rating: $A$

\section{Case four}

A 15-year-old obese Hispanic male with subclinical hypothyroidism and AIT $(\mathrm{TSH}=6.72 \mu \mathrm{lU} / \mathrm{mL}$, reference range $=0.35-5.5 \mu \mathrm{IU} / \mathrm{mL}$; and positive thyroid peroxidase antibody $75 \mathrm{lU} / \mathrm{ml}$, reference range $0-35 \mathrm{IU} / \mathrm{ml}$ ) had a significant family history of thyroid disease. The father and a maternal cousin had autoimmune hypothyroidism and the mother and maternal cousin had thyroid cancer. On exam, the patient's thyroid was not enlarged and there were no palpable nodules or cervical lymphadenopathy, however, examination was limited by body habitus.

Based on the strong family history of thyroid cancer, ultrasound was performed, revealing a $1.8 \times 1.6 \times 0.8 \mathrm{~cm}$ hypoechoic nodule contained punctate hyperechoic foci as well as multiple suspicious cervical lymph nodes. ${ }^{14,15}$ Total thyroidectomy and central compartment LND revealed a $1.5 \mathrm{~cm}$ PTC in a background of Iymphocytic thyroiditis with Iymph node metastasis; TNM stage pT1bN1aMx.

This case raised the following questions.

- Should a family history of PTC prompt additional evaluation in children?

- Should a thyroid ultrasound be performed in patients with AIT when there are no nodules or abnormal lymph nodes palpated?

PTC is a common endocrine tumor and many pedigrees have at least one relative with PTC. The risk of familial, non-medullary thyroid cancer increases when two first degree relatives have DTC, approaching a $96 \%$ likelihood of an inherited disorder when three or more first degree relatives have DTC. ${ }^{48}$ However, even if PTC were limited to the mother, the probability of having children with PTC is 4.5-fold more common (OR, $\mathrm{Cl}=1.2-19.8, \mathrm{p}=0.045$ ). ${ }^{49}$ The risk is even greater (odds ratio $[\mathrm{OR}]=7.4$, range 1.8-30.4) if that relative is a sibling. ${ }^{50}$ In these families, ultrasound surveillance identifies tumors with smaller size $(0.8 \mathrm{~cm}$ vs. $2.85 \mathrm{~cm}$; $p<0.001$ ), a lower incidence of extrathyroidal extension (20.9\% vs. 56.2\%; $\mathrm{p}=0.002)$, and a lower incidence of lymph node metastasis $(23.2 \%$ vs. 65.6\%; $p<0.001) .{ }^{51}$ The ATA pediatric thyroid cancer guidelines offer no clear recommendations for prospective screening (beyond routine physical examination) in most families containing a member with PTC. ${ }^{12}$ However, this may change in future versions of the guidelines and there are updated recommendations for US screening for both the PTEN Hamartoma Tumor Syndrome, DICER-1 related disorders, and APCAssociated familial adenomatous polyposis. ${ }^{52}$

The second question raised by these data is whether or not patients with autoimmune thyroid disease warrant ultrasound, even if they do not have a suspicious thyroid gland by physical exam. Corrias, et al. ${ }^{2}$ performed ultrasound on 365 young patients with autoimmune thyroid 
disease and found 115 thyroid nodules (31.5\%), of which, only 38 (onethird) were palpable. There were 11 PTC (10\% of all nodules or $3 \%$ of all patients). Growth of a nodule while the patient was taking levothyroxine and abnormal lymphadenopathy were more common in those with PTC. Kambalapalli, et al., performed ultrasound on 154 children with goiter but without any palpable nodules. ${ }^{3}$ They found nodules in 20/154 patients (13\%) and PTC in $4 / 20$ nodules (20\%) or $4 / 154$ patients (2.6\%). None of the PTC were palpable, although one was $>2 \mathrm{~cm}$ in diameter and two had microscopic regional lymph node involvement (N1). The ATA pediatric thyroid cancer guidelines suggest that a suspicious-feeling thyroid gland warrants ultrasound examination. ${ }^{12}$ This leaves open the possibility to perform ultrasound but it is not imperative.

\section{RECOMMENDATION 4(D)}

For patients with AIT, evaluation by an experienced thyroid ultrasonographer should be pursued in any patient with a suspicious thyroid examination (suspected nodule or significant gland asymmetry), especially if associated with palpable cervical lymphadenopathy. ${ }^{12}$ Recommendation rating: $\mathrm{B}$

In this particular patient, there were many factors that support the use of ultrasound: obesity limiting adequate examination, autoimmune thyroid disease, and a family history of PTC in a first degree relative.

\section{Case five}

A 10-year-old Hispanic male underwent resection of a thyroglossal duct cyst that was found to contain incidental PTC. Neck US showed no other evidence for disease and the patient had no further surgery or medical therapy at that time. Five years later, PTC recurred in the submental and submandibular lymph nodes. The patient underwent a Sistrunk procedure, total thyroidectomy, and bilateral modified radical neck dissection at levels II, III, and IV. Final pathology confirmed PTC in 10/84 lymph nodes but there was no PTC in the thyroid gland. Following surgery he received $97 \mathrm{mCi}^{131} \mathrm{l}$ and the post-therapy whole body scan showed uptake only in the thyroid bed. The patient was started on levothyroxine and has had a declining but persistent stimulated serum $\operatorname{Tg}(4.6-1.1 \mathrm{ng} / \mathrm{ml})$.

This case raised several different questions.

- What evaluations of the thyroid gland and neck are appropriate for PTC in a thyroglossal duct cyst?

- What is optimal treatment for PTC in a thyroglossal duct cyst?

- What should be done for a persistent low-level but detectable serum Tg?

There are few published series of PTC in thyroglossal duct remnants in adults ${ }^{53,54}$ and only one in children. ${ }^{55}$ Thyroid cancer is found in $0.7-1.5 \%$ of thyroglossal duct cysts in adults and $88.5 \%$ are PTC. In adults, $61.5 \%$ of patients also have PTC in the thyroid gland, $30 \%$ show extension into soft tissue, and $88.2 \%$ have regional lymph node involvement. However, the lymph node involvement often follows a different pattern depending on the location of the thyroglossal duct remnant. Lesions near or above the thyroid cartilage are associated with metastasis to level 1 and 2 rather than the central compartment (level 6) or levels 2, 3, and 4 in the lateral neck and level 6, which are more typcial for intrathyroid PTC.53 Carter, et al., recommended ultrasound examination of the thyroid gland and neck nodes, and total thyroidectomy only if there was invasion of the wall, aggressive histology, or ultrasound findings indicating disease in the gland. ${ }^{54}$ In pediatric patients, coincidental PTC appears to occur less frequently than in adults. Pfeiffer, et al. studied 26 cases in children. ${ }^{55}$ Although $7 \%$ of the population have thyroglossal duct remnants, cancer occured in only $1 \%$ of thyroglossal duct remnants. The vast majority (22/26 cases) were PTC. Although $50 \%$ had cervical lymph node metastases, none of 13 patients who had total thyroidectomy had PTC in the thyroid gland. For children, they recommended the Sistrunk procedure plus local LND, but TT only for evidence of disease in the thyroid.

In this case, initial surgery did not include the Sistrunk procedure, or dissection of the cervical nodes. Recurrence in the regional nodes appeared five years later, consistent with the data outlined above. There was no evidence for PTC in the gland, which is also consistent with the published series in children.

Following therapy, the patient has had a persistent but declining serum $\mathrm{Tg}$. This indicates persistent but low level disease that has been difficult to localize (See recommendations $23 \mathrm{~A}-\mathrm{E}$ in Case One above). Continued surveillance in this situation is appropriate.

\section{Case six}

A 16-year-old female had a palpable thyroid nodule and hyperthyroidism (TSH $<0.01 \mu \mathrm{lU} / \mathrm{mL}$, total T4 $=16.1 \mu \mathrm{g} / \mathrm{dL}$, free $\mathrm{T} 4=3.0 \mathrm{ng} / \mathrm{dL}$ and total T3 $=322 \mathrm{ng} / \mathrm{dL}$ ). Thyroid ultrasound revealed a $4.2 \times 1.8 \mathrm{~cm}$ heterogeneous partially cystic nodule in the right lobe and a $1.6 \times 0.7 \times 1.0 \mathrm{~cm}$ nodule in the left lobe. Due to the suppressed TSH, thyroid uptake and scan were obtained showing increased uptake (53\%) in the right lobe and minimal uptake in the remainder of the thyroid consistent with a hyperfunctioning nodule. Right hemithyroidectomy was performed revealing a $2.2 \mathrm{~cm}$ encapsulated well differentiated PTC without capsular or lymphovascular invasion. During follow up, FNA of the left thyroid nodule was performed and revealed indeterminate cytology (Atypia of Undetermined Significance [AUS]—Bethesda III Category). The Afirma gene expression classifier ([GEC] Veracyte, 7000 Shoreline Court, Suite 250, South San Francisco, CA 94080) was benign. With repeat surveillance ultrasound, the left thyroid nodule (AUS) remains unchanged in size or appearance.

This case raised the following questions.

- What is the incidence of PTC in hyperfunctioning nodules in children?

- Does PTC in a hyperfunctioning nodule have the same prognosis?

- What is the risk of malignancy in lesions with AUS?

- How effective are 'gene expression classifiers' in pediatric tumors?

- Is there a role for completion thyroidectomy on the remaining left side?

Autonomous nodules in children may be associated with somatic activating mutations within the genes encoding the TSH receptor or the GSalpha subunit. ${ }^{57}$ In adults, treatment options include ${ }^{131}$ I ablation, surgical resection, or ethanol injection. Because of concerns of the mutagenic effect of low-activity radioiodine on the surrounding normal thyroid, and the fact that one third of patients have an incidentally discovered DTC, surgical resection is usually recommended for pediatric patients with autonomous nodules. ${ }^{12}$ There are no data to indicate a different prognosis for children with PTC in autonomous nodules. 


\section{RECOMMENDATION 9}

For pediatric patients with a suppressed TSH and a thyroid nodule, thyroid scintigraphy should be pursued. Increased uptake within the nodule is consistent with autonomous function. Surgical resection, most commonly lobectomy, is the recommended approach for most autonomous nodules in children and adolescents. Recommendation rating: $A$

In adults, the risk of malignancy in indeterminate nodules ranges from $\sim 5$ to $15 \%$ in the AUS/ Follicular Lesion of Undetermined Significance (FLUS) category and 15 to $30 \%$ in the follicular neoplasm or suspicious for neoplasm group. ${ }^{58}$ The limited data available suggest these indeterminate categories account for approximately $35 \%$ of pediatric FNA and that, in children, $28 \%$ of AUS/FLUS lesions and $58 \%$ of suspicious for follicular or Hürthle cell neoplasm are malignant. ${ }^{19,59}$

In adults, molecular testing aids in the management of thyroid nodules with indeterminate cytology. ${ }^{60}$ However, molecular studies have not been validated in pediatric patients, although mutational analysis has been used to examine thyroid nodules in limited numbers of children. ${ }^{19,61}$ Approximately $17 \%$ of pediatric FNAs have a mutation or rearrangement that correlates with malignancy in $100 \% .{ }^{19}$ However, the cytological classification for these tumors were AUS/FLUS, suspicious for follicular or Hürthle neoplasm, suspicious for malignancy, or malignant, all of which would require surgical removal regardless of the mutational analysis.

\section{RECOMMENDATION 6}

A positive mutational test appears highly likely to be associated with malignancy. Conversely, insufficient data exist in children to rely on negative genetic studies to reliably exclude malignancy. Although molecular studies hold promise for complementing the results of FNA, particularly for nodules that yield indeterminate cytology, they have not yet been sufficiently validated in children and cannot be routinely recommended in routine clinical practice until further studies are conducted. ${ }^{12}$ Recommendation rating: $\mathrm{E}$

Although a proprietary multigene expression classifier has been validated to corroborate a benign diagnosis in adults with indeterminate nodules, this panel is only approved for patients $>21$ years of age. There are no studies determining the accuracy of the gene expression classifier in the evaluation of the indeterminate pediatric thyroid nodule. Therefore, although current molecular diagnostics might improve the diagnostic acumen for indeterminate cytology in children, additional studies are required before a formal recommendation can be offered or incorporation into clinical practice.

For pediatric patients with PTC, there is a $25 \%$ risk of bilateral disease even if undetected by thyroid US. This patient incurred damage to the recurrent laryngeal nerve during the initial lobectomy. For that reason, despite the potential risk for bilateral disease, the family agreed to purusue US surveillance of the remaining nodule with repeat FNA if indicated.

\section{Case seven}

A 10-year-old male presented with a two- to three-month history of neck mass. CT scan showed bilateral scattered enlarged lymph nodes in the anterior and posterior neck. A lymph node biopsy revealed PTC and the patient underwent total thyroidectomy with extensive bilateral LND. Pathology showed: dsvPTC with extrathyroidal invasion at both anterior and posterior margins, extensive lympho-vascular invasion, and 27/74 lymph nodes infiltrated by PTC. Five weeks after surgery, a dxWBS (123|) with rhTSH preparation showed uptake in two left neck foci and a thyroglossal duct remnant. An 18fluorodeoxy glucose positron emission tomography (FDG-PET) scan showed low-level focal uptake in the right supraclavicular and paratracheal areas. CT of the chest identified seven small (3-5 mm) lung nodules. The tumor was classified as T3 N1b M1.

The patient was treated with ${ }^{131}(58.6 \mathrm{mCi})$ following two doses of recombinant TSH $(0.9 \mathrm{mg}$ each injection). At the time of therapy, the serum TSH was $458 \mu \mathrm{IU} / \mathrm{mL}$ and the serum Tg was $384 \mathrm{ng} / \mathrm{ml}$.

Residual disease was noted seven months after the initial therapy with a right supraclavicular node and a conglomerate mass in the right paratracheal region. Due to progressive growth of this mass, he underwent a second surgery to remove the mass and 2/10 lymph nodes which were involved with PTC.

Fifteen months after the initial surgery he began treatment with the mitogen activated protein kinase (MEK) inhibitor (trametinib at a dose of $0.025 \mathrm{mg} / \mathrm{kg}$ ).

This case raised the following questions:

- What is a working definition of iodine refractory disease in children?

- How do we best treat low-iodine avid disease?

- What is the role for dosimetry in patients with pulmonary metastases?

- Is there a role for empiric RAI?

- Is there a role for FDG-PET in children?

- Should additional surgery be performed to remove macroscopic neck disease prior to RAl for pulmonary metastases?

- At what point do we consider treatment with alternate therapies like tyrosine kinase inhibitors (TKIS) or MEK inhibitors?

The ATA pediatric thyroid cancer guidelines suggest that treatment of residual disease should be based on multiple factors and individualized to the patient's age, risk stratification, and history of prior treatment and response to treatment. ${ }^{12}$

In adults, iodine refractory disease as adapted from Dadu and Cabanillas, $2012^{62}$ is defined as follows.

- Disease does not take up RAl at known sites of metastatic disease.

- Disease that grows despite ${ }^{131} \mathrm{l}$ and confirmed uptake.

- Disease that grows over a 1 year period after ${ }^{131}$.

- The patient has received a cumulative ${ }^{131} \mid>600 \mathrm{mCi}$ and has persistent disease.

However, iodine refractory disease has not been defined for children. It is useful to remember that disease-specific mortality for DTC in children is less than $3 \%$ and long-term survival is $>97 \% .{ }^{63}$ Even in children with pulmonary metastasis, a combination of surgery, ${ }^{131}$ | therapy, and TSH suppression results in complete (47.32\%) or partial (38.39\%) response in the majority of children. Only $14.29 \%$ of children with pulmonary 
metastases fail to show any response to treatment. ${ }^{63}$ Approximately $30-45 \%$ of children with pulmonary metastases develop stable but persistent disease following surgery and ${ }^{131}$ therapy. ${ }^{8}$ Based on these facts and the fact that ${ }^{131}$ may continue to have an effect for many years after treatment in children, the ATA pediatric thyroid cancer guidelines state that an undetectable Tg level should no longer be the sole goal of treatment of children with pulmonary metastases. ${ }^{12}$

\section{RECOMMENDATION 28(A)}

The decision to treat or to observe structural cervical disease should be individualized and include considerations of age, initial ATA

Pediatric Risk classification, the presence of distant metastases, and prior treatment history (including complications), in addition to the size, extent, anatomic location and iodine avidity. Recommendation rating: $\mathrm{C}$

\section{RECOMMENDATION 28(B)}

Children with macroscopic cervical disease ( $>1 \mathrm{~cm}$ in size) should be assessed by a high-volume thyroid surgeon to determine the feasibility of additional surgery. Recommendation rating: $\mathrm{B}$

\section{RECOMMENDATION 28(C)}

Iodine-avid cervical disease (visualized with dxWBS) could be treated with surgery or ${ }^{131}$ I depending on risks and the presence or absence of distant metastases. Surgery would be favored for disease localized to the neck, especially if located in a lymph node compartment not previously operated upon. Recommendation rating: $\mathrm{B}$

\section{RECOMMENDATION 28(D)}

If repeat surgery is performed, postoperative re-staging can be utilized to determine whether additional ${ }^{131}$ I treatment is warranted, especially in the patient who has not received previous therapeutic ${ }^{131}$. Recommendation rating: $\mathrm{C}$

As reviewed in case one, the dxWBS is not as sensitive for detecting disease as is the serum Tg level. A negative $\mathrm{dxWBS}$ does not prove absence of disease nor can it be used as evidence for iodine refractory disease. Metastatic PTC in Iymph nodes typically has reduced RAI absorption. For that reason, there may be increased lymph node uptake when higheractivities of RAl are given. It is not entirely clear however, if this will achieve tumoricidal effect on bulky lymph node metastasis. Bulky lymph node uptake also reduces the efficacy of RAI to treat pulmonary metastases. For these reasons, it is prudent to re-operate (if possible) to remove all residual neck disease prior to ${ }^{131}$ therapy.

Without a clear definition of iodine reractory disease in children, continued treatment for pulmonary metastases should be given only to those who show signs of progression (increase in tumor size as detected by anatomic imaging or serum Tg) and documented clinical response to previous ${ }^{131}$ | therapy. If the patient has no evidence of cervical disease, low urine iodine excretion, and still shows no uptake of ${ }^{131}$ I into the pulmonary lesions, then it is unlikely that a higher or additional doses of ${ }^{131}$ I would benefit. At that point, if the patient displays progressive, RAI refractory pulmonary or non-surgical disease, one may consider systemic therapy.

For adult patients with iodine refractory disease, there is an increasing number of molecular targeted therapies. The agents target protein tyrosine kinase dependent pathways and are collectively referred to as multi-kinase inhibitors (TKIS). ${ }^{64}$ TKIs have been studied in adults with advanced PTC and
FTC, medullary thyroid cancer (MTC) and anaplastic thyroid caricinoma. ${ }^{64}$ For adults with an increased risk of disease-specific mortality, the benefit of extending PFS is significant. As an example, phase II trials of sorafenib have response rates up to $30 \%$ with median PFS between $58-79$ weeks. ${ }^{64}$ The Double-Blind Randomized Phase III Study Evaluating the Efficacy and Safety of Sorafenib Compared to Placebo in Locally Advanced/Metastatic RAIRefractory Differentiated Thyroid Cancer (DECISION) trial reported a 12\% response rate and an increase in median PFS from 5.8 to 10.8 months. ${ }^{65}$ More recently, the Multicenter, Randomized, Double-Blind, Placebo-Controlled, Phase 3 Trial of Lenvatinib (E7080) in ${ }^{131}$-Refractory Differentiated Thyroid Cancer (SELECT) trial reported increased PFS for FTC (28.8 months vs. 2.4 months for placebo) and PTC (16.4 months vs. 3.5 months for placebo). ${ }^{66}$ Almost $75 \%$ of patients responded within 30 -days after intitiatng treatment and four of the 169 patients achieved complete remission. An increasing list of additional TKIs are currently in phase II clinical trials.67,68

\section{RECOMMENDATION 29(A)}

Children with RAl-avid pulmonary metastases visualized with a DxWBS are good candidates for ${ }^{131}$ therapy. Recommendation rating: $A$

\section{RECOMMENDATION 29(B)}

After a therapeutic activity of ${ }^{131}$, the TSH-suppressed $\mathrm{Tg}$ level and imaging studies should be monitored until the nadir clinical and biochemical ( $\mathrm{Tg}$ ) response is reached. Recommendation rating: $\mathrm{B}$

\section{RECOMMENDATION 29(C)}

If the nadir clinical and biochemical (Tg) response suggests persistent disease or if there is documented disease progression $>12$ months after ${ }^{131}$ I therapy, further evaluation with a DxWBS and a TSH-stimulated $\mathrm{Tg}$ is indicated. Recommendation rating: $\mathrm{B}$

\section{RECOMMENDATION 29(D)}

Re-treatment of RAl-avid pulmonary metastases should be considered in children who have demonstrated progression of disease and a previous response to ${ }^{131}$. Treatment with ${ }^{131}$ I should be performed by experts with experience in managing children with pulmonary metastases. Recommendation rating: $\mathrm{B}$

\section{RECOMMENDATION 29(E)}

Re-treatment of pulmonary metastases with ${ }^{131}$ is not recommended in children who do not have uptake on a dxWBS and who have not demonstrated a previous response to ${ }^{131}$. Recommendation rating: $\mathrm{E}$

\section{RECOMMENDATION 29(F)}

Pulmonary function testing should be considered in all children with diffuse pulmonary metastases, especially if multiple ${ }^{131}$ I treatments are planned. ${ }^{1}$ Recommendation rating: C

One exciting area is redifferentiation therapy, which is designed to increase expression of the sodium-iodine symporter (NIS). Retinoic acid was initially tried but found to be ineffective. 69,70 More recently, the MEK 1/MEK 2 inhibitor (selective mitogen-activated extracelluar signalregulated kinase), selumetinib (75 mg twice daily $x 4$ weeks), was shown to increase RAI uptake to the threshold required for ${ }^{131}$ treatment in eight of 12 patients with NRAS or BRAF mutations. ${ }^{71}$ Trametinib, the MEK inhibitor used in this particular case has a similar target. Although trametinib appears to be effective in treating BRAF mutant malignant melanoma, ${ }^{72}$ there is only one study examining its potential effectiveness in thyroid cancer cell-lines and a xenograft mouse-model. ${ }^{73}$ 
Four TKIs have received FDA approval for use in adults with advanced thyroid cancer; sorafenib and lenvatinib for DTC, and vandetanib and carbozantinib for MTC. ${ }^{74}$ Phase I and II trials have also been conducted to determine the safety and efficacy of sorafenib in pediatric patients with refractory solid tumors or leukemias. ${ }^{75,76}$ However, no children with PTC were enrolled into either of the pediatric sorafenib trials $\mathrm{s}^{75,76}$ and there is only limited or anectodotal experience in using molecular therapies in children.77,78 $\mathrm{A}$ small phase I/II trial of vandetanib in pediatric patients with locally advanced or metastatic MTC reported partial response in 12/16 patients (decrease in calcitonin) and 8/16 subjects (decrease in carcinoembryonic antigen). ${ }^{79}$

With the exception of vandetinib for treatment of advanced MTC, none of these agents have been examined in the pediatric population for the treatment of progressive, non-RAl responsive disease. All of these agents have significant toxicities and even in adults with progressive, RAl-refratory disease, none of these agents improves overall survival. ${ }^{64}$ National clinical trials are needed to determine which pediatric patients would benefit from systemic therapy as well as the best strategy for their clinical use.

\section{RECOMMENDATION 31}

Most children with asymptomatic and non-progressive ${ }^{131} \mid$-refractory disease can be safely monitored while continuing TSH suppression. Systemic treatment for advanced thyroid cancer in children remains unstudied and at this time should be considered the purview of specialized centers for the treatment of children with thyroid cancer. ${ }^{1}$ Recommendation rating: $\mathrm{C}$

The 18FDG-PET/CT scan is increasingly used in the evaluation of adults with persistent non iodine-avid thyroid cancer ${ }^{80-82}$ and appears to offer prognostic information that might change clinical management. ${ }^{83}$ However, there are limited data regarding the use of 18FDG-PET/CT in children, except for a case report, isolated pediatric subjects embedded within adult studies, and unpublished observations. These reports suggest low sensitivity of 18FDG$\mathrm{PET} / \mathrm{CT}$ to identify disease in children that cannot be identified with US and cross-sectional imaging (Personal communication, SGW). Whether or not the 18F-FDG PET has similar prognostic value or will change disease management in children with thyroid cancer remains to be determined.

\section{RECOMMENDATION 26(A)}

For the child with a detectable TSH-suppressed Tg but a negative ultrasound and dxWBS, contrast-enhanced cross sectional imaging of the neck and chest should be considered once iodine excess has been eliminated as a cause of a false negative dxWBS. Recommendation rating: $B$

\section{RECOMMENDATION 26(B)}

The utility of 18FDG-PET/CT is poorly studied in pediatric DTC and 18FDG-PET/CT cannot be routinely recommended in the care of children who have persistent evidence of DTC on follow-up. Recommendation rating: $D$

\section{RECOMMENDATION 26(C)}

Empiric ${ }^{131}$ I therapy and a post-treatment scan are not recommended to localize disease in the child with a negative DxWBS unless there is evidence for clinical progression (e.g. a rising $\mathrm{Tg}$ level) and a documented clinical response to previous ${ }^{131}$ therapy.1 Recommendation rating: $\mathrm{D}$

\section{Case eight}

A 14-year-old with Hashimoto's thyroiditis was found to have a $3 \mathrm{~cm}$ PTC in the right lobe that was densely adherent to the strap muscles and trachea. He underwent TT, central LND and dissection of the right lateral neck (levels 2-4). A total of 24/71 central nodes contained tumor and 1/3 lateral nodes contained tumor. He was treated with $130.6 \mathrm{mCi}{ }^{131} \mathrm{l}$ and the post-therapy scan showed multifocal areas of persistent uptake in the left neck (contralateral). Eight months later, the basal serum Tg was 11 ng/ml (negative Tg-Ab) and repeat surgery removed 41 lymph nodes from the left neck ( $5 / 41$ contained tumor). The basal $(\mathrm{Tg}=5.7 \mathrm{ng} / \mathrm{ml}$ ) and TSH-stimulated Tg levels $(79.6 \mathrm{ng} / \mathrm{ml})$ remained elevated. Despite that, US, neck and chest MRI, PET scan, and dxWBS failed to identify disease. After four years, empiric RAl therapy (191.4 mCi ${ }^{131}$ ) was given. Post-therapy scan and singlephoton emission computed tomography (SPECT-CT) showed uptake in the lungs that was not visible on CT, suggesting micro-nodular metastasis. After his second RAl therapy, the basal Tg was detectable but lower (1.6 and $3.5 \mathrm{ng} / \mathrm{ml}$ ).

This last case raised several unique questions.

- Why did imaging fail to show disease with a stimulated serum Tg of $79.6 \mathrm{ng} / \mathrm{ml}$ ?

- Is there a role for 'empiric' RAl therapy and if so, at what point?

- How is it best to follow and or treat, now that basal Tg is low but still detectable?

This case demonstrates the extensive regional lymph node involvement that can occur in pediatric patients and underscores the importance of pre-operative staging, well-executed surgical resection, and the need for reassessment if the surveillance Tg does not decrease. Micrometastasis to regional lymph nodes may be difficult to visualize on pre-operative ultrasound and MRI, although this is very uncommon. Initial surgery removed central and right lateral nodes that contained tumor but surveillance Tg suggested persistent disease. This was only identified by post-therapy ${ }^{131}$ I scan and confirmed during left lateral neck dissection.

It is difficult to determine why all imaging modalities failed to identify disease with a serum $\mathrm{Tg}$ of $79.6 \mathrm{ng} / \mathrm{ml}$. Highly sensitive immunometric assays for $\mathrm{Tg}$ are more sensitive for detecting disease in adults than dxWBS. ${ }^{29}$ However, in one pediatric study, ultrasound and dxWBS equally identified lymph node metastases in the majority of patients (35/45). However, in six patients, lymph node metastases were found only with a post-treatment WBS. ${ }^{84}$

Previous studies of children with DTC have focused on the dxWBS as the 'gold-standard' for disease detection, and there are few data regarding the interpretation of Tg levels in children with DTC. Children with PTC who have residual/recurrent disease are most likely to have cervical lymph node disease. US, in conjunction with serum $\mathrm{Tg}$, has proven highly effective in identifying and localizing regional nodal metastases in both adults and children with PTC and may even be more sensitive than a TSHstimulated Tg to identify disease. ${ }^{85}$ (Recommendation 23 A-E in case one) As in the previous case, there are few data regarding the use of 18FDG$\mathrm{PET} / \mathrm{CT}$ in children with DTC. 86 
Finally, empiric treatment with ${ }^{131}$ does not appear to be effective in adults who have a negative $\mathrm{dxWBS}{ }^{87,88}$ Although children are more likely to have RAl-responsive disease, empiric treatment with ${ }^{131}$ is is not generally advocated to identify disease, unless there is evidence for clinical progression (e.g. a rising Tg level) and a documented response to previous ${ }^{131}$ therapy. In select cases such as this, with rising serum $\mathrm{Tg}(1.6-3.5 \mathrm{ng} / \mathrm{ml})$, no evidence of surgically resectable disease, and previous response to ${ }^{131}$ therapy (decline in serum $\mathrm{Tg}$ ) empiric was indicated and helped identify micro-nodular pulmonary metastasis.

\section{Conclusion}

The authors of this series of cases hope that their presentation and discussion have been informative and will help to illustrate how the ATA Pediatric Thyroid Cancer Guidelines can be applied to case management. For full details of the ATA Treatment Guidelines for Children with Differentiated Thyroid Cancer, the reader is referred to the Management Guidelines for Children with Thyroid Nodules and Differentiated Thyroid Cancer. ${ }^{12}$
1. Avula S, Daneman A, Navarro OM, et al., Incidental thyroid abnormalities identified on neck US for non-thyroid disorders, Pediatr Radiol, 2010;40(11):1774-80.

2. Corrias A, Cassio A, Weber G, et al., Thyroid nodules and cance in children and adolescents affected by autoimmune thyroiditis, Arch Pediatr Adolesc Med, 2008;162(6):526-531.

3. Kambalapalli M, Gupta A, Prasad UR, Francis GL, Ultrasound characteristics of the thyroid in children and adolescents with goiter a single center experience, Thyroid, 2015;25(2):176-82

. Niedziela M, Pathogenesis, diagnosis and management of thyroid nodules in children, Endocr Relat Cancer, 2006;13(2):427-53

5. Hayat MJ, Howlader N, Reichman ME, Edwards BK, Cance statistics, trends, and multiple primary cancer analyses from the Surveillance, Epidemiology, and End Results (SEER) Program, Oncologist, 2007:12(1):20-37.

6. Cooper DS, Doherty GM, Haugen BR, et al., Revised American Thyroid Association management guidelines for patients with thyroid nodules and differentiated thyroid cancer, Thyroid 2009:19(11):1167-1214.

7. Hay ID, Gonzalez-Losada T, Reinalda MS, et al., Long-term outcome in 215 children and adolescents with papillary thyroid cancer treated during 1940 through 2008, World J Surg 2010;34(6):1192-1202.

8. La Quaglia MP, Black T, Holcomb GW, et al., Differentiated thyroid cancer: clinical characteristics, treatment, and outcome in patients under 21 years of age who present with distant metastases. A report from the Surgical Discipline Committee of the Children's Cancer Group, J Pediatr Surg, 2000;35(6):955-9; discussion 960.

9. Biko J, Reiners C, Kreissl MC, et al., Favourable course of disease after incomplete remission on (131)! therapy in children with pulmonary metastases of papillary thyroid carcinoma: 10 years follow-up, Eur J Nucl Med Mol Imaging, 2011:38(4):651-5.

10. Cooper DS, Doherty GM, Haugen BR, et al., Management guidelines for patients with thyroid nodules and differentiated thyroid cancer, Thyroid, 2006;16(2):109-42.

11. Haugen BR, Alexander EK, Bible KC, et al., 2015 American Thyroid Association Management Guidelines for Adult Patients with Thyroid Nodules and Differentiated Thyroid Cancer: The American Thyroid Association Guidelines Task Force on Thyroid Nodules and Differentiated Thyroid Cancer, Thyroid, 2016:26(1):1-133.

12. Francis GL, Waguespack SG, Bauer AJ, et al., Management Guidelines for Children with Thyroid Nodules and Differentiated Thyroid Cancer, Thyroid, 2015;25(7):716-59.

13. U.S. Preventive Services Task Force Ratings: Grade Definitions. Available at: www.uspreventiveservicestaskforce.org/3rduspstf/ ratings.htm (accessed April 6, 2016).

14. Lyshchik A, Drozd V, Demidchik Y, Reiners C, Diagnosis of thyroid cancer in children: value of gray-scale and power doppler US, Radiology, 2005:235(2):604-13.

15. Leboulleux S, Girard E, Rose M, et al., Ultrasound criteria of malignancy for cervical lymph nodes in patients followed up for differentiated thyroid cancer, J Clin Endocrinol Metab, 2007;92(9):3590-4.

16. Pinchot $\mathrm{SN}$, Al-Wagih $\mathrm{H}$, Schaefer $\mathrm{S}$, et al., Accuracy of fineneedle aspiration biopsy for predicting neoplasm or carcinoma in thyroid nodules $4 \mathrm{~cm}$ or larger, Arch Surg, 2009:144(7):649-55.

17. McCoy KL, Jabbour N, Ogilvie JB, et al., The incidence of cancer and rate of false-negative cytology in thyroid nodules greater than or equal to $4 \mathrm{~cm}$ in size, Surgery, 2007;142(6):837-44; discussion 844 e831-3.

18. Wharry LI, McCoy KL, Stang MT, et al., Thyroid nodules $(>/=4$ $\mathrm{cm})$ : can ultrasound and cytology reliably exclude cancer? World I Surg 2014:38(3):614-21.

19. Monaco $S E$, Pantanowitz $L$ Khalbuss WE, et al. Cytomorphological and molecular genetic findings in pediatric thyroid fine-needle aspiration, Cancer Cytopathol, 2012:120(5):342-50

20. Smith M, Pantanowitz L, Khalbuss WE, et al., Indeterminate pediatric thyroid fine needle aspirations: a study of 68 cases, Acta Cytol, 2013;57(4):341-8.

21. Baskin $\mathrm{HJ}$, Detection of recurrent papillary thyroid carcinoma by thyroglobulin assessment in the needle washout after fine-needle aspiration of suspicious lymph nodes, Thyroid 2004:14(11):959-63.

22. Boi F, Baghino G, Atzeni F, et al., The diagnostic value for differentiated thyroid carcinoma metastases of thyroglobulin
(Tg) measurement in washout fluid from fine-needle aspiration biopsy of neck lymph nodes is maintained in the presence of circulating anti-Tg antibodies, J Clin Endocrinol Metab, 2006;91(4):1364-9.

23. Cunha N, Rodrigues F, Curado F, et al., Thyroglobulin detection in fine-needle aspirates of cervical lymph nodes: a technique for the diagnosis of metastatic differentiated thyroid cancer, Eur J Endocrinol, 2007:157(1):101-7.

24. Frasoldati A, Pesenti M, Gallo M, et al., Diagnosis of neck recurrences in patients with differentiated thyroid carcinoma, Cancer, 2003;97(1):90-6

25. Giovanella L, Bongiovanni M, Trimboli P, Diagnostic value of thyroglobulin assay in cervical lymph node fine-needle aspirations for metastatic differentiated thyroid cancer, Curr Opin Oncol, 2013;25(1):6-13.

26. Robbins RJ, Srivastava S, Shaha A, et al., Factors influencing the basal and recombinant human thyrotropin-stimulated serum thyroglobulin in patients with metastatic thyroid carcinoma, J Clin Endocrinol Metab, 2004;89(12):6010-6.

27. Spencer CA, Clinical Utility of Thyroglobulin Antibody (TgAb) Measurements for Patients with Differentiated Thyroid Cancers (DTC), J Clin Endocrinol Metab, 2011;96(12):3615-27.

28. Verburg FA, Luster M, Cupini C, et al., Implications of thyroglobulin antibody positivity in patients with differentiated thyroid cancer: a clinical position statement, Thyroid, 2013:23(10):1211-25

29. Mazzaferri EL, Robbins RJ, Spencer CA, et al. A consensus report of the role of serum thyroglobulin as a monitoring method for low-risk patients with papillary thyroid carcinoma J Clin Endocrinol Metab, 2003;88(4):1433-41.

30. Padovani RP, Robenshtok E, Brokhin M, Tuttle RM, Even without additional therapy, serum thyroglobulin concentrations often decline for years after total thyroidectomy and radioactive remnant ablation in patients with differentiated thyroid cancer, Thyroid, 2012:22(8):778-83.

31. Pillai S, Gopalan V, Smith RA, Lam AK, Diffuse sclerosing variant of papillary thyroid carcinoma--an update of its clinicopathological features and molecular biology, Crit Rev Oncol Hematol, 2015;94(1):64-73.

32. Koo JS, Hong S, Park CS, Diffuse sclerosing variant is a major subtype of papillary thyroid carcinoma in the young, Thyroid 2009;19(11):1225-31.

33. Fukushima $\mathrm{M}$, Ito $\mathrm{Y}$, Hirokawa $\mathrm{M}$, Akasu $\mathrm{H}$, et al., Clinicopathologic characteristics and prognosis of diffuse sclerosing variant of papillary thyroid carcinoma in Japan: an 18-year experience at a single institution, World I Surg, 2009;33(5):958-62.

34. Brink JS, van Heerden JA, Mclver B, et al., Papillary thyroid cancer with pulmonary metastases in children: long-term prognosis, Surgery, 2000:128(6):881-6: discussion 886-887.

35. Knudsen N, Christiansen E, Brandt-Christensen M, et al., Ageand sex-adjusted iodine/creatinine ratio. A new standard in epidemiological surveys? Evaluation of three different estimates of iodine excretion based on casual urine samples and comparison to $24 \mathrm{~h}$ values, Eur J Clin Nutr, 2000;54(4):361-3.

36. Hoofnagle AN, Roth MY, Clinical review: improving the measurement of serum thyroglobulin with mass spectrometry, I Clin Endocrinol Metab, 2013:98(4):1343-52.

37. Malandrino $P$, Latina A, Marescalco $S$, et al., Risk-adapted management of differentiated thyroid cancer assessed by a sensitive measurement of basal serum thyroglobulin, J Clin Endocrinol Metab, 2011;96(6):1703-9.

38. Smallridge RC, Meek SE, Morgan MA, et al., Monitoring thyroglobulin in a sensitive immunoassay has comparable sensitivity to recombinant human tsh-stimulated thyroglobulin in follow-up of thyroid cancer patients, J Clin Endocrinol Metab 2007:92(1):82-7.

39. Chiovato L, Latrofa F, Braverman LE, et al., Disappearance of humoral thyroid autoimmunity after complete removal of thyroid antigens, Ann Intern Med, 2003;139(5 Pt 1):346-51.

40. Bhatti P, Veiga $L H$, Ronckers $C M$, et al., Risk of second primary thyroid cancer after radiotherapy for a childhood cancer in a large cohort study: an update from the childhood cance survivor study, Radiation Research, 2010;174(6):741-52.

41. Taylor AJ, Croft AP, Palace AM, et al., Risk of thyroid cancer in survivors of childhood cancer: results from the British Childhood Cancer Survivor Study, Int 1 Cancer, 2009;125(10):2400-5.

42. Nikiforov $Y E$, Nikiforova MN, Molecular genetics and diagnosis of thyroid cancer, Nat Rev Endocrinol 2011:7(10):569-80.

43. Veiga LH, Bhatti P, Ronckers CM, et al., Chemotherapy and thyroid cancer risk: a report from the childhood cancer survivor study, Cancer Epidemiol Biomarkers Prev, 2012;21(1):92-101.

44. de Vathaire $F$, Francois $\mathrm{P}$, Schlumberger M, et al.,

Epidemiological evidence for a common mechanism for neuroblastoma and differentiated thyroid tumour, $\mathrm{Br}$ I Cancer. 1992:65(3): $425-8$

45. van Santen HM, de Kraker J, van Eck BL, et al., High incidence of thyroid dysfunction despite prophylaxis with potassium iodide during ${ }^{\left({ }^{13}\right)}$ )-meta-iodobenzylguanidine treatment in children with neuroblastoma, Cancer, 2002;94(7):2081-9.

46. Clement SC, van Eck-Smit BL, van Trotsenburg AS, et al., Long-term follow-up of the thyroid gland after treatment with ${ }^{131}$-Metaiodobenzylguanidine in children with neuroblastoma: importance of continuous surveillance, Pediatr Blood Cancer, 2013:60(11):1833-8

47. Buryk MA, Picarsic JL, Creary SE, et al., Identification of Unique, Heterozygous Germline Mutation, STK11 (p.F354L), in a Child with an Encapsulated Follicular Variant of Papillary Thyroid Carcinoma within Six Months of Completing Treatment for Neuroblastoma, Pediatr Dev Pathol, 2015;18(4):318-23.

48. Charkes ND, On the prevalence of familial nonmedullary thyroid cancer in multiply affected kindreds, Thyroid, 2006:16(2):181-6.

9. Zivaljevic $\mathrm{V}$, Tausanovic $\mathrm{K}$, Sipetic $\mathrm{S}$, et al., A case-control study of papillary thyroid cancer in children and adolescents, Eur J Cancer Prev, 2013;22(6):561-5.

50. Xu L, Li G, Wei Q, et al., Family history of cancer and risk of sporadic differentiated thyroid carcinoma, Cancer, 2012;118(5):1228-35.

51. Rosario PW, Mineiro Filho AF, Prates BS, et al., Ultrasonographic screening for thyroid cancer in siblings of patients with apparently sporadic papillary carcinoma, Thyroid 2012:22(8):805-8

52. Robenshtok E, Tzvetov G, Grozinsky-Glasberg S, et al., Clinical characteristics and outcome of familial nonmedullary thyroid cancer: a retrospective controlled study, Thyroid, 2011;21(1):43-8.

53. Pellegriti G, Lumera G, Malandrino P, et al., Thyroid cancer in thyroglossal duct cysts requires a specific approach due to its unpredictable extension, J Clin Endocrinol Metab, 2013;98(2):458-65

54. Carter $\mathrm{Y}$, Yeutter $\mathrm{N}$, Mazeh $\mathrm{H}$, Thyroglossal duct remnant carcinoma: beyond the Sistrunk procedure, Surg Oncol, 2014:23(3):161-6

55. Pfeiffer MS, Kim GH, Krishnan M, Thyroglossal duct papillary carcinoma in a 15-year old female and review of pediatric case of thyroglossal duct carcinoma, Int J Pediatr Otorhinolaryngol, 2014;78(1):135-8

56. Cibas ES, Ali SZ, The Bethesda System for Reporting Thyroid Cytopathology, Thyroid, 2009:19(11):1159-65.

57. Schwab KO, Pfarr N, van der Werf-Grohmann N, et al Autonomous thyroid adenoma: only an adulthood disease? Pediatr, 2009;154(6):931-3; e932.

58. Sohn YM, Kim EK, Moon HJ, et al., Suspiciously malignan findings on ultrasound after fine needle aspiration biopsy in a thyroid nodule with initially benign ultrasound and cytologic result: to repeat or to follow-up, Clin Imaging, 2011;35(6):470-5.

59. Baloch ZW, LiVolsi VA, Asa SL, et al., Diagnostic terminology and morphologic criteria for cytologic diagnosis of thyroid lesions: a synopsis of the National Cancer Institute Thyroid Fine-Needle Aspiration State of the Science Conference, Diagn Cytopathol 2008:36(6):425-37.

60. Nikiforov YE, Ohori NP, Hodak SP, et al., Impact of mutational testing on the diagnosis and management of patients with cytologically indeterminate thyroid nodules: a prospective analysis of 1056 FNA samples, J Clin Endocrinol Metab, 2011:96(11):3390-7.

61. Ferraz C, Eszlinger M, Paschke R, Current state and future perspective of molecular diagnosis of fine-needle aspiration biopsy of thyroid nodules, I Clin Endocrinol Metab, 2011;96(7):2016-26

62. Dadu R, Cabanillas ME, Optimizing therapy for radioactive iodine-refractory differentiated thyroid cancer: current state of the art and future directions, Minerva Endocrinol, 2012;37(4):335-56.

63. Pawelczak M, David R, Franklin B, et al., Outcomes of children and adolescents with well-differentiated thyroid carcinom and pulmonary metastases following (1)(3)(1)I treatment: a systematic review, Thyroid, 2010;20(10):1095-101. 
64. Covell LL, Ganti AK, Treatment of advanced thyroid cancer: role of molecularly targeted therapies, Targeted Oncology , 2015;10(3):311-24

65. Brose MS, Nutting CM, Jarzab B, et al., Sorafenib in radioactive iodine-refractory, locally advanced or metastatic differentiated thyroid cancer: a randomised, double-blind, phase 3 trial, Lancet, 2014;384(9940):319-28

66. Schlumberger $\mathrm{M}$, Tahara $\mathrm{M}$, Wirth $\mathrm{L}$, et al., Lenvatinib versus placebo in radioiodine-refractory thyroid cancer, $N$ Eng/ J Med 2015;372(7):621-30

67. Worden F Treatment strategies for radioactive iodinerefractory differentiated thyroid cancer, Ther Adv Med Oncol, 2014;6(6):267-79.

68. Gruber JJ, Colevas AD, Differentiated thyroid cancer: focus on emerging treatments for radioactive iodine-refractory patients, Oncologist, 2015;20(2):113-26.

69. Coelho SM, Corbo R, Buescu A, et al., Retinoic acid in patients with radioiodine non-responsive thyroid carcinoma, J Endocrino Invest, 2004:27(4):334-9.

70. Handkiewicz-Junak D, Roskosz J, Hasse-Lazar K, et al., 13-cisretinoic acid re-differentiation therapy and recombinant human thyrotropin-aided radioiodine treatment of non-Functiona metastatic thyroid cancer: a single-center, 53-patient phase 2 study, Thyroid Research, 2009;2(1):8.

71. Ho AL, Grewal RK, Leboeuf R, et al., Selumetinib-enhanced radioiodine uptake in advanced thyroid cancer, $N$ Eng/ I Med 2013;368(7):623-32

72. Lugowska I, Kosela-Paterczyk H, Kozak K, et al., a MEK inhibito for management of metastatic melanoma, Onco Targets and Therapy, 2015:8:2251-9.
73. Ball DW, Jin N, Xue P, et al., Trametinib with and without pazopanib has potent preclinical activity in thyroid cancer Oncol Rep, 2015;34(5):2319-24.

74. Weitzman SP, Cabanillas ME, The treatment landscape in thyroid cancer: a focus on cabozantinib, Cancer Manag Res, 2015;7:265-78

75. Kim A, Widemann BC, Krailo M, et al., Phase 2 trial of sorafenib in children and young adults with refractory solid tumors: A report from the Children's Oncology Group, Pediatr Blood Cancer, 2015;62(9):1562-6.

76. Widemann BC, Kim A, Fox E, et al, A phase I trial and pharmacokinetic study of sorafenib in children with refractory solid tumors or leukemias: a Children's Oncology Group Phase Consortium report, Clin Cancer Res, 2012;18(21):6011-22.

77. Iyer P, Mayer JL, Ewig JM, Response to sorafenib in a pediatric patient with papillary thyroid carcinoma with diffuse nodular pulmonary disease requiring mechanical ventilation, Thyroid, 2014;24(1):169-74.

78. Waguespack SG, Sherman SI, Williams MD, et al.. The successfu use of sorafenib to treat pediatric papillary thyroid carcinoma, Thyroid, 2009:19(4):407-12.

79. Fox E, Widemann BC, Chuk MK, et al., Vandetanib in children and adolescents with multiple endocrine neoplasia type $2 \mathrm{~B}$ associated medullary thyroid carcinoma, Clin Cancer Res, 2013;19(15):4239-48.

80. Dong MJ, Liu ZF, Zhao K, et al., Value of 18F-FDG-PET/PET-CT in differentiated thyroid carcinoma with radioiodine-negative whole-body scan: a meta-analysis, Nucl Med Commun 2009:30(8):639-50.

81. Miller ME, Chen $\mathrm{Q}$, Elashoff $\mathrm{D}$, et al., Positron emission tomography and positron emission tomography-CT evaluation for recurrent papillary thyroid carcinoma: meta-analysis and literature review, Head Neck, 2011;33(4):562-65.

82. Bannas $P$, Derlin T, Groth M, et al., Can (18)F-FDG-PET/CT be generally recommended in patients with differentiated thyroid carcinoma and elevated thyroglobulin levels but negative I-13 whole body scan?, Ann Nucl Med, 2012;26(1):77-85.

83. Robbins RJ, Wan Q, Grewal RK, et al., Real-time prognosis for metastatic thyroid carcinoma based on 2-[18F]fluoro-2-deoxyD-glucose-positron emission tomography scanning, J Clin Endocrinol Metab, 2006:91(2):498-505.

84. Antonelli A, Miccoli P, Fallahi P, et al., Role of neck ultrasonography in the follow-up of children operated on for thyroid papillary cancer, Thyroid, 2003;13(5):479-484

85. Waguespack SG, Francis G, Initial management and follow-up of differentiated thyroid cancer in children, I Natl Compr Canc Netw, 2010;8(11):1289-300

86. Armstrong S, Worsley D, Blair GK, Pediatric surgical images: PET evaluation of papillary thyroid carcinoma recurrence, J Pediatr Surg, 2002;37(11):1648-9.

87. Kim WG, Ryu JS, Kim EY et al. Empiric high-dose 131-iodine therapy lacks efficacy for treated papillary thyroid cancer patients with detectable serum thyroglobulin, but negative cervical sonography and 18F-fluorodeoxyglucose positron emission tomography scan, J Clin Endocrinol Metab, 2010;95(3):1169-73

88. Fatourechi V, Hay ID, Javedan $\mathrm{H}$, et al., Lack of impact of radioiodine therapy in tg-positive, diagnostic whole-body scannegative patients with follicular cell-derived thyroid cancer, 」 Clin Endocrinol Metab, 2002:87(4):1521-6. 